\title{
Raymond Carver: Vandali / S engleskog prevela Ana Tomčić
}

Carol i Robert Norris bili su stari prijatelji Nickove žene Joanne. Upoznali su se davno, mnogo prije nego što je ona upoznala Nicka. Poznavali su je kada je bila udana za Billa Dalyja. U ono vrijeme njih četvero - Carol i Robert, Joanne i Bill - friško oženjeni studenti na zadnjoj godini povijesti umjetnosti - živjeli su u istoj kući, velikoj kući na Seattleovoj verziji Capitol Hilla, dijelili stanarinu i kupaonicu. Često su zajedno jeli i sjedili do sitnih sati, pili vino i razgovarali. Jedni su drugima pregledavali i komentirali radove. Tijekom te zadnje godine zajedničkog života - prije nego što se pojavio Nick - čak su kupili jeftin brodić kojim su ljeti zajedno plovili jezerom Washington. "Kakva su to vremena bila, i dobra i loša, puna uspona i padova”, rekao je Robert drugi put toga jutra osmjehujući se i promatrajući lica prijatelja za stolom.

Bila je nedjelja ujutro, a oni su sjedili za stolom u kuhinji Nicka i Joanne u Aberdeenu i jeli dimljeni losos, kajganu i peciva sa sirnim namazom. Bio je to onaj isti losos kojeg je Nick uhvatio prošlog ljeta i vakumirao i stavio u duboko zamrzavanje. Sviđalo mu se kad je Joanne naglasila da je on sam ulovio tu ribu. Čak je znala - ili je barem tvrdila da zna - koliko je teška. "Ova je imala osam kila", rekla je, a Nick se zadovoljno nasmijao. Sinoć je izvadio ribu iz zamrzivača nakon što je nazvala Carol i rekla da bi ona i Robert rado svratili sa svojom kćerkicom Jenny kad budu u prolazu.

"Smijemo ići?" upitala je Jenny. "Idemo se voziti na skejtbordu."

"Skejtovi su u autu”, rekla je Jennyna prijateljica Megan.

"Prvo odnesite tanjure u sudoper", odgovorio je Robert. "A onda možete ići. Ali nemojte daleko. Ostanite tu u blizini. I pazite se", dodao je.

"Misliš da je u redu?" upitala je Carol.

"Naravno", odgovorila je Joanne. "Nema problema. Da bar ja imam skejtbord, pridružila bih im se." 
"Ali uglavnom su to bila dobra vremena", nastavio je Robert svoju tiradu o studentskim danima. "Je l' da?" upitao je pogledavši Joanne i nacerivši se od uha do uha.

Joanne je kimnula.

"E, da, to su bili dani”, rekla je sad Carol.

Nick je imao osjećaj da ih Joanne želi pitati nešto o Billu Dallyju. Ali nije. Osmjehnula se i, zadržavši osmijeh sekundu predugo, upitala je li netko za još kave.

“Ja bih mogao još malo, hvala”, rekao je Robert. "A-a”, rekla je Carol i dlanom prekrila šalicu. Nick je odmahnuo glavom.

"I? Reci mi što je s tim lososima?" obratio se Robert Nicku.

"Nema se tu što previše reći", odgovorio je Nick. "Rano ustaneš, odeš na vodu i onda, ako ne puše vjetar ili ne pljušti kiša i riba je tamo, a ti imaš dobru opremu, možda i uhvatiš nešto. Ako imaš sreće, u prosjeku ćeš uloviti svaku četvrtu koja zagrize. Neki su ljudi valjda u stanju tome posvetiti čitav život, ja malo pecam ljeti, i to je to."

“A ideš barkom ili kako?” upitao je Robert. Pitao je to onako usput. Ustvari, to ga uopće nije zanimalo, ali morao je nastaviti kad je već otvorio temu. Barem je Nick imao takav osjećaj. "Idem, da", odgovorio je. "Na vezu je dolje u marini."

Robert je polako kimnuo. Joanne mu je natočila kavu, a Robert ju je pogledao i osmjehnuvši se dobacio: "Hvala, srećo!"

Nick i Joanne viđali su se s Robertom i Carol otprilike svakih šest mjeseci - Nick je morao priznati da je to češće nego što je njemu osobno odgovaralo. Nije da mu nisu bili dragi, jesu. Ustvari, sviđali su mu se više od ostalih Joanneinih prijatelja. Sviđao mu se Robertov gorak smisao za humor i način na koji je svaku priču bio u stanju učiniti smješnijom nego što je vjerojatno bila. I Carol mu se sviđala. Ljepuškasta, vesela žena koja bi tu i tamo još uvijek naslikala pokoji akrilik - u sobi Nicka i Joanne visjela je jedna od njenih slika koju su dobili na poklon. Kad god su bili zajedno, Carol je uvijek bila ljubazna prema Nicku. Ali ponekad, dok bi se Robert i Joanne prisjećali prošlosti, Nick bi osjetio potrebu da pogleda prema Carol na drugom kraju sobe, a ona bi 
mu uzvratila pogled i nasmijala se kao da mu želi reći da ovim pričama iz prošlosti ne pridaje preveliku važnost.

Pa ipak, s vremena na vrijeme kad bi ovako sjedili zajedno, Nick nije mogao odagnati osjećaj da ga potiho osuđuju i da mu Robert, ako ne i Carol, još zamjera što je uništio Billov i Joannein brak i tako okončao njihova sretna druženja u četvero.

Viđali su se barem dvaput godišnje u Aberdeenu, jednom negdje na početku ljeta i jednom pred kraj. Robert, Carol i Jenny, njihova desetogodišnja kći, skrenuli bi do grada na putu prema Olimpijskom poluotoku, šumovitom predjelu gdje bi unajmili kućicu u mjestu zvanom Ahatna Plaža, a Jenny bi u kožnu torbicu skupljala ahat i ostalo kamenje koje će zatim dati ispolirati u Seattleu.

Njih troje nikad ne bi ostali prespavati kod Nicka i Joanne - Nicku je palo na pamet da im zapravo nitko nikad nije ni ponudio da prenoće, iako je bio uvjeren da bi in Joanne rado ugostila kad bi Nick to predložio. Ali on to nije učinio. Robert i Carol svaki put bi u posjet došli u vrijeme doručka ili taman prije ručka. Carol bi uvijek ranije nazvala da se dogovore. Uvijek su bili točni i Nick je to cijenio.

Sviđali su mu se, ali nekako se uvijek osjećao neugodno u njihovu društvu. Nikad u njegovoj prisutnosti nisu pričali o Billu Dallyju, čak mu ni ime nisu spominjali. Unatoč tome, Nicku je bilo jasno da je tijekom ovih zajedničkih sastanaka Bill Dally bio svima u glavi. Nick je Billu Dallyju oteo ženu, a sada su oni, Billovi prijatelji, boravili u istoj kući s čovjekom koji je počinio taj besramni zločin i na neko vrijeme njihove živote izbacio iz tračnica. Nije li to neka vrsta izdaje od strane Roberta i Carol, da se druže s čovjekom koji je to učinio? Da s njim dijele kruh i gledaju ga kako s ljubavlju polaže ruku na rame žene koja je ranije bila udana za njihova voljenog prijatelja? "Nemojte ići daleko, dušo", upozorila je Carol Jenny kad su djeca opet prolazila kuhinjom. "Još malo pa idemo."

"Nećemo", rekla je Jenny. "Samo tu ispred."

"Stvarno nemojte dalje", dodao je Robert pogledavajući na sat. "Uskoro krećemo."

Vrata su se zatvorila za djecom, a odrasli su se vratili temi koje su se već dotakli toga jutra terorizmu. Robert je predavao likovni u srednjoj školi u Seattleu, a Carol je radila u butiku kraj 
tržnice Pike Place. Nisu poznavali nikoga tko je tog ljeta putovao u Europu ili na Srednji istok. Ustvari, nekolicina njihovih prijatelja otkazala je putovanja u Italiju i Grčku.

"Prvo upoznaj Ameriku, to je moj moto", rekao je Robert. Zatim je pričao o svojoj majci i očuhu koji su se upravo vratili s dvotjednog izleta u Rim. Prtljaga im je nestala na tri dana, to je prva stvar koja je pošla po zlu. Onda, druge večeri, njegovoj je majci džepar na biciklu ukrao torbicu dok su hodali prema restoranu nedaleko od hotela - na cesti punoj patrola u uniformama sa strojnicama. Dva dana kasnije, kada su u unajmljenom autu otišli na izlet tridesetak kilometara od Rima, netko im je probušio gumu i ukrao haubu dok su bili u muzeju. "Razumiješ, nisu ukrali akumulator ili tako nešto", čudio se Robert. "Htjeli su haubu. Pa sad ti to meni objasni."

"Pa što će im hauba?" pitala se Joanne.

"Tko zna", rekao je Robert. "Ali u svakom slučaju, otkako smo bacili bombe, stvari su se pogoršale, za turiste, mislim. Što vi uopće mislite o bombardiranju? Ja mislim da će to za Amerikance samo još otežati situaciju. Sada je svatko potencijalna meta."

Nick je promiješao kavu i otpio gutljaj, a zatim rekao: "Ne znam više ni sam. Stvarno ne znam. Još mi se po glavi motaju sva ona tjelesa na aerodromima u lokvama krvi. Jednostavno ne znam." Opet je promiješao kavu. "Ljudi s kojima sam pričao misle da smo trebali baciti još koju bombu kad smo već počeli. Čuo sam neke koji kažu da smo ih trebali sravniti sa zemljom. Ja ne znam što smo točno trebali ili nismo trebali napraviti. Ali morali smo učiniti nešto, barem ja tako mislim."

"Pa nije li to ipak malo prežestoko, baš sve sravniti sa zemljom? Kao da smo bacili nuklearku, ne?" "Kažem da ne znam što su trebali učiniti. Ali morali smo nekako odgovoriti na to što se dogodilo." “Diplomacija”, predložio je Robert. "Ekonomske sankcije. Neka ih opale po novčaniku. Pa će se smiriti i letjeti ravno."

“Da skuham još kave?" upitala je Joanne. "Gotova je za minutu. Tko hoće još dinje?" Povukla je stolicu unatrag i ustala od stola.

"Ne mogu više ni zalogaj", rekla je Carol.

"Ni ja”, rekao je Robert. "Pun sam." Činilo se da želi nastaviti s temom, ali onda se ipak predomislio. 
"Nick, moram jednom doći ovamo pecati s tobom. Kada je najbolja sezona?"

"Samo dođi”, rekao je Nick. "Možeš doći bilo kad i ostati koliko god želiš. Srpanj je najbolji. A i kolovoz. Čak i prvih tjedan-dva u rujnu." Počeo je pričati o tome kako je najbolje pecati navečer kad se sve barke već pokupe. Počeo je pričati o tome kako je jednom uhvatio kapitalca na mjesečini.

Činilo se da Robert neko vrijeme odvaguje ovu zamisao. Otpio je malo kave. "I hoću. Doći ću ovog ljeta - u srpnju, ako je to u redu."

"Sasvim u redu", rekao je Nick.

"A što će mi trebati?" interesirao se Robert.

"Samo ponesi sebe. Ja imam dovoljno opreme", rekao je Nick.

"Možeš koristiti moj štap", ponudila je Joanne.

"Ali onda ti ne bi mogla pecati”, rekao je Robert. I tu je razgovor o pecanju naglo stao. Pomisao da bi morali satima sjediti u istom čamcu bila je neugodna i Nicku i Robertu. Ne, iskreno nije mogao zamisliti da bi njihov odnos ikad mogao otići dalje od sjedenja u ovoj ugodnoj kuhinji dvaput godišnje uz doručak i šalicu kave. Taj je dio doduše bio prilično ugodan, ali to je bilo sasvim dovoljno. Više od toga jednostavno nije bilo u kartama. U zadnje je vrijeme čak propustio nekoliko izleta u Seattle s Joanne jer je znao da će na kraju dana htjeti svratiti do Roberta i Carol na kavu. Nick bi tada izmislio neki izgovor i ostao kod kuće. Rekao bi da ima previše posla u pilani, gdje je radio kao voditelj. Jednom prilikom Joanne je ostala prespavati kod Roberta i Carol i kada se vratila, nekoliko se dana doimala neobično zamišljeno i distancirano. Kad ju je pitao kako je bilo, rekla je da je bilo dobro i da su nakon večere sjedili i razgovarali do kasno u noć. Nick je znao da su razgovarali o Billu Dalyju, bio je siguran u to, i zbog toga je nekoliko tjedana bio ljut. Ali zašto ga smeta što pričaju o Billu Dalyju? Joanne sad pripada njemu. Nekada bi ubio za nju. Još uvijek je voli i ona voli njega, ali sad više nije do te mjere opsjednut. Ne, danas ne bi ubio za nju i bilo mu je teško zamisliti da je jednom uopće osjećao takvo što. Sad mu se više ne čini vrijednom ubijanja, kao ni bilo tko drugi kad smo kod toga.

Joanne je ustala i počela raspremati stol. 
“Daj da ti pomognem”, rekla je Carol.

Nick je Joanne obavio oko struka i privukao je k sebi kao da ga je pomalo sram misli koje su mu netom pobjegle. Joanne je stajala mirno blizu Nickove stolice. Dopustila mu je da je zagrli. A onda se zacrvenjela i odmaknula u stranu. Nick ju je pustio.

Jenny i Megan otvorile su vrata i ušle u kuhinju sa svojim skejtbordima. "Tamo dolje gori vatra", rekla je Jenny.

“U nečijoj kući je požar", dodala je Megan.

"Vatra?" upitala je Carol. "Ako je prava vatra, onda je se klonite."

“Nisam čula vatrogasce," primijetila je Joanne. "Ljudi, jeste vi nešto čuli?”

“Nisam ni ja”, rekao je Robert. "Idite se igrati, djeco. Nećemo još dugo."

Nick je otišao do prozora i pogledao van. Nije mogao primijetiti ništa neuobičajeno. Pomisao na požar u kvartu u jedanaest ujutro ovog sunčanog dana činila mu se nepojmljivom. Osim toga, nije čuo nikakav alarm, nikakva zvona, buku sirena ni skvičanje kočnica, nije vidio aute pune znatiželjnika. Nick je zaključio da je sve samo dječja smicalica.

"Ovo je bio divan doručak", rekla je Carol. "Predobar. Sad bih se baš mogla izvaliti i malo prileći." "Pa zašto ne?" upitala je Joanne. "Gore je slobodna soba. Djecu pustite da se igraju, a vi se otiđite malo odmoriti prije puta."

"Pa da", rekao je Nick. "Samo dajte."

“Carol se samo šalila, naravno", rekao je Robert. "Ne bismo mogli. Je l' da, Carol?" Robert ju je pogledao.

“Ne, ne baš”, rekla je Carol i nasmijala se. "Ali sve je bilo tako lijepo, kao i uvijek. Kraljevski doručak, samo bez šampanjca."

“Takvi su najbolji”, rekao je Nick. Nick je prestao piti prije šest godina, nakon što je završio u zatvoru zbog vožnje u alkoholiziranom stanju. Jedanput ga je netko odveo u društvo liječenih alkoholičara, shvatio je da je na pravome mjestu i otada je odlazio onamo svake večeri, ponekad $\mathrm{i}$ dvaput u jednoj večeri, i tako dva mjeseca, sve dok ga želja za alkoholom nije ostavila "kao da je 
nikad nije ni bilo", kako je sam znao reći. Čak i danas, iako više nema problema s alkoholom, povremeno ode na sastanak.

"A kad smo već kod alkohola", ubacio se Robert, "sjećate se Harryja Schustera - doktora Schustera, sada radi na transplantaciji koštane srži, ne pitajte me kako - uglavnom, sjećate se onog božićnog tuluma kad se Schuster posvadio sa svojom ženom?"

"Marilyn”, rekla je Joanne. "Marilyn Schuster. Umalo sam zaboravila na nju."

"Marilyn, tako je", rekao je Robert. "Mislio je da je previše popila i da se nabacuje..."

Tu je napravio dovoljno dugu stanku da bi Joanne rekla: "Billu".

"Billu, da", potvrdio je Robert. "Prvo su se porječkali, a onda je ona bacila ključeve na pod dnevne sobe i rekla: 'Onda ti vozi kad si tako jebeno siguran, trijezan i pouzdan!' I tako je Harry - a pazi, došli su s dva auta jer je on internirao u bolnici - Harry je, dakle, najprije uzeo njezin auto, odvezao se dva bloka dalje, parkirao, onda se vratio po svoj auto, odvezao ga dva bloka dalje, parkirao, pa se opet odšetao do njenog auta, odvezao ga dva bloka dalje, parkirao, vratio se po svoj auto i odvezao ga malo dalje... i parkirao i vratio se po njen auto i odvezao ga, i tako dalje i tako dalje." Svi su se smijali. I Nick se smijao. Stvarno je bilo smiješno. Nick je čuo mnoge priče, ali nijednu s ovakvim preokretom.

"Uglavnom", nastavio je Robert, "štono se kaže, da skratim, odvezao je oba auta do kuće. Trebala su mu neka dva, tri sata za osam kilometara. Kad se vratio, Marilyn ga je već čekala s pićem u ruci. Netko ju je odbacio doma. 'Sretan Božić', rekla mu je čim je ušao kroz vrata. Mislim da ju je onda zviznuo."

Carol je zazviždala. A Joanne rekla: "Svi su odmah vidjeli da to s njih dvoje neće ići. Oboje su živjeli brzo i žestoko. Godinu dana kasnije opet su bili na istom tulumu, samo s drugim partnerima." “Kolike sam pijane vožnje ja prošao", rekao je Nick. Odmahnuo je glavom. "A samo su me jednom priveli."

“Imao si sreće”, rekla je Joanne.

“Netko drugi je imao sreće”, ispravio ju je Robert. "Na primjer, drugi vozači koji su se tada našli na cesti." 
"Jednu noć sam proveo u zatvoru", rekao je Nick. "To je bilo dovoljno. Onda sam prestao. Ustvari, bio sam na takozvanom "čišćenju”. Sljedećeg jutra došao je doktor - zvao se Forester - i jednog po jednog nas pozvao u ured na pregled. Pregledao bi ti oči svjetiljkom, rekao da ispružiš ruke s dlanovima prema gore, izmjerio puls i poslušao srce. Onda bi ti održao kratku lekciju o pijanstvu i obavijestio te kad ćeš biti pušten. Rekao je da smijem otići u jedanaest. "Doktore", pitao sam ga, "mogu li otići malo ranije?" "Čemu žurba?" upitao je. "Moram u jedanaest biti u crkvi “, rekao sam. "Ženim se."

“I što je rekao na to?" pitala je Carol.

“Rekao je: 'Gubi se odavde, mladiću. Ali da ovo nisi zaboravio, je l' ti jasno?' I nisam. Prestao sam piti. Čak ni na vlastitoj svadbi tog popodneva nisam ništa popio. Ni kapi. To je bilo to. Previše sam se bojao. Ponekad je potrebno tako nešto, neki šok, nešto da te prodrma, da se stvari okrenu." “Imao sam mlađeg brata kojeg je skoro ubio pijani vozač”, rekao je Robert. “Još je na aparatima i mora koristiti metalnu protezu za kretanje."

“Zadnje prijave za kavu”, rekla je Joanne.

“Samo još malo", rekla je Carol. "Stvarno moramo pokupiti klince i put pod noge."

Nick je gledao kroz prozor i vidio nekoliko automobila kako prolaze ulicom. Ljudi su žurno hodali pločnikom. Sjetio se da su Jenny i njezina prijateljica spomenule neku vatru, ali, pobogu, da negdje gori, valjda bi se čule sirene i vatrogasna kola! Htio je ustati od stola, ali ipak nije.

"Ludo je sve to", rekao je. "Sjećam se kad sam još pio i doživio svoj prvi napadaj. Pao sam i udario glavom o stolić. Srećom, bio sam kod doktora kad se to dogodilo. Probudio sam se na krevetu u njegovu uredu, a Peggy, moja tadašnja žena, nagnula se nad mene zajedno s doktorom i sestrom. Peggy me dozivala. Na glavi sam imao neki ogroman zavoj, kao turban. Doktor mi je rekao da sam upravo doživio svoj prvi napadaj i da ću ih, nastavim li piti, po svoj prilici doživjeti još. Rekao sam mu da sam naučio lekciju. Ali to sam rekao reda radi. Tada još nisam imao namjeru prestati. Sebe i ženu uvjeravao sam da su za moju nesvjesticu krivi živci i stres."

"Tog istog dana Peggy i ja smo pripremali zabavu koju smo isplanirali nekoliko tjedana unaprijed $\mathrm{i}$ nismo ni pomišljali na mogućnost da je u zadnji čas otkažemo i razočaramo sve pozvane. Zamislite 
to! I tako smo mi održali svoju zabavu i svi su došli, a ja sam još uvijek bio u zavojima. Cijelu sam noć proveo s čašom votke u ruci, a ljudima sam rekao da sam porezao glavu kad sam se slučajno udario u vrata."

“Koliko si još pio nakon toga?" upitala je Carol.

"Dosta dugo, godinu dana, tako nešto. Dok me nisu pokupili onu večer."

"Bio je trijezan kad sam ga upoznala", rekla je Joanne i pocrvenjela kao da je rekla nešto što ne bi smjela.

Nick je položio ruku oko njenog vrata i zadržao je ondje. Izdvojio je pramen kose rasute po vratu i počeo ga vrtjeti među prstima. Neki su ljudi prolazili pločnikom kraj prozora. Većina in je nosila bluze i kratke rukave. Jedan čovjek na ramenima je nosio malu djevojčicu.

"Prestao sam piti godinu dana prije nego što sam upoznao Joanne", rekao je Nick kao da im govori nešto što bi trebali znati.

"Pričaj im o bratu, dušo", rekla je Joanne. Nick isprva nije rekao ništa. Prestao joj je masirati vrat i povukao ruku.

"Što se dogodilo?" pitao je Robert naginjući se.

Nick je odmahnuo glavom.

"Što?" upitala je Carol. "Nick, sve je u redu, mislim, ako nam želiš reći."

"Kako smo uopće došli na tu temu?" pitao se Nick.

"Ti si započeo", podsjetila ga je Joanne.

"Pa eto, pokušavao sam ostati trijezan i shvatio sam da to neće ići kod kuće, ali nisam htio nekamo otići, na primjer, u neku kliniku ili instituciju za odvikavanje, a brat je imao vikendicu koju nije koristio - bio je listopad - pa sam ga nazvao i pitao smijem li otputovati onamo na tjedan-dva da se saberem. Isprva je pristao i već sam se počeo pakirati i bio sretan što imam obitelj i brata koji će mi pomoći. Ali onda je zazvonio telefon, javio sam se i brat mi je priopćio da ne zna kako da mi ovo kaže, ali da se on i njegova žena boje da bih mogao izazvati požar u vikendici - razgovarao je s njom ranije. Mogao bih, rekao je, negdje ostaviti upaljenu cigaretu ili zaboraviti ugasiti plin. $U$ svakom slučaju, boje se da ću im zapaliti kuću, njemu je jako žao, ali ipak mi ne može pomoći.” 
"Ajme", rekla je Carol. "I brat ti je to učinio? Ostavio te na cjedilu, tvoj vlastiti brat."

"Ne znam što bih ja napravio na njegovu mjestu", rekao je Nick.

"Naravno da znaš", usprotivila se Joanne.

"A valjda znam, da", odgovorio je Nick. "Naravno da bih mu dao da bude ondje. K vragu i kuća. Mislim, to je samo kuća? Uvijek možeš dobiti lovu od osiguranja."

"Stvarno šokantna priča", rekao je Robert. "A kako se danas slažete, ti i brat?"

“Nikako, bojim se. Zamolio me da mu posudim nešto novaca, ima tome već dosta. I posudio sam mu, vratio mi je na vrijeme. Ali nismo se vidjeli pet godina. Ženu mu nisam vidio i dulje od toga." "Ma odakle dolaze svi ti ljudi?" pitala se Joanne. Ustala je od stola, otišla do prozora i razmaknula zavjese.

"Djeca su pričala nešto o vatri”, napomenuo je Nick.

“To je smiješno", rekla je Joanne. "Nemoguće da stvarno gori. Ili?"

"Nešto se događa", rekao je Robert.

Nick je otišao do ulaznih vrata i otvorio ih. Neki je auto usporio i zaustavio se na nogostupu pred kućom. Drugi je parkirao preko puta. Grupice ljudi prolazile su spuštajući se niz ulicu. Nick je izašao u dvorište, a ostali - Joanne, Carol i Robert - odmah za njim. Pogledao je niz ulicu i vidio dim, hrpu ljudi, dvoja vatrogasna kola i policijski auto parkiran na raskrižju. Ljudi su šmrkovima pokušavali obraniti olupinu kuće - bila je to kuća Carpenterovih, Nicku ju je odmah prepoznao. Crni dim sukljao je sa zidova, na krovu je buktjela vatra. "Bože dragi, stvarno požar", rekao je. "Djeca su bila u pravu."

"Ali kako nismo ništa čuli?" pitala se Joanne. "Jeste vi što čuli? Ja nisam."

"Moramo odmah pokupiti cure, Roberte", upozorila je Carol. "Možda nekome smetaju, a možda i stanu preblizu vatre. Svašta bi se moglo dogoditi."

I tako se njih četvero uputilo pločnikom. Upali su u skupinu ljudi koji su hodali laganim korakom. Hodali su s tim ljudima. Nicku se činilo da su na izletu. Ali sve to vrijeme nisu skidali pogled s kuće u plamenu i vatrogasaca koji su mlaz usmjerili na krov, gdje je i dalje gorjelo. Neki drugi vatrogasci 
crijevo su držali tako da je mlaz vode prolazio kroz prednji prozor. Vatrogasac u kacigi privezanoj ispod brade, dugom crnom kaputu i crnim čizmama do koljena nosio je sjekiru i kretao se prema stražnjem dijelu kuće.

Došli su do skupine ljudi koja je promatrala prizor. Policijski auto bio je ukoso parkiran nasred ceste, čuli su cvrčanje radija iz auta i u pozadini zvuk plamena koji proždire zidove. Onda je Nick spazio djevojčice, stajale su u prednjem dijelu grupe sa skejtbordima u rukama. "Eno ih", rekao je Robertu. "Tamo gore, vidiš in?"

Probijali su se kroz rulju mrmljajući isprike i tako stigli do djece.

"Vidiš?" rekla je Jenny. "Rekle smo vam." Megan je u jednoj ruci držala skejtbord, palac druge ruke stavila je u usta.

"Znate li što se dogodilo?" pitao je Nick ženu u pletenom šeširu koja je stajala kraj njega i pušila cigaretu.

"Vandali", odgovorila je. "Barem su mi tako rekli."

"Ako se mene pita, treba ih ubiti čim ih uhvate", rekao je čovjek koji je stajao kraj nje. "Ili ih zaključati i onda baciti ključ. Ti ljudi sada putuju po Meksiku. Ni ne znaju da se nemaju kamo vratiti. Nisu ih uspjeli kontaktirati. Jadni ljudi. Zamisli to, dođeš kući i onda ti kažu da je više nema."

"Sad će pasti!" povikao je vatrogasac sa sjekirom. "Odmaknite se!"

Nitko od njih nije stajao blizu njega ili kuće, ali ljudi su se svejedno pomaknuli. Nick je osjećao kako u njemu raste napetost. "O bože, o bože."

"Pogledaj ti to", rekao je netko iz mase.

Nick se pomaknuo bliže Joanne koja se zagledala u vatru. Kosa na njezinu čelu bila je mokra. Zagrlio ju je. Dok ju je grlio, shvatio je kako to čini već treći put ovoga jutra.

Nick se polako okrenuo prema Robertu i iznenadio se kad je shvatio da Robert, umjesto u kuću, bulji u njega. Lice mu je bilo crveno, izraz ozbiljan, kao da je sve što se dogodilo - požar, zatvor, preljub i izdaja, remećenje ustaljenog poretka - bila Nickova krivica i odgovornost. Nick ga je gledao, još uvijek grleći Joanne, sve dok crvenilo nije napustilo Robertovo lice, a on spustio 
pogled. Kad ga je ponovo podigao, nije više gledao Nicka. Primaknuo se svojoj ženi kao da je želi zaštititi.

Nick i Joanne još uvijek su stajali zagrljeni, ali Nick je imao onaj poznati osjećaj koji bi mu dolazio s vremena na vrijeme kad bi ga njegova žena odsutno potapšala po ramenu. Da ne zna što misli. “O čemu razmišljaš?” upitao ju je.

"Razmišljam o Billu”, rekla je.

Još uvijek ju je grlio. Neko je vrijeme šutjela, a onda rekla: "Znaš, često mislim na njega. Ipak je on bio prvi muškarac kojeg sam voljela."

I dalje su ostali zagrljeni. Spustila je glavu na njegovo rame i tako su nastavili gledati kuću koju je proždirao plamen.

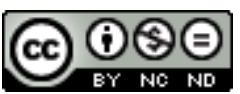

Creative Commons Attribution-NonCommercial-NoDerivatives 4.0 International License 